\title{
Urethral Sphincter
}

National Cancer Institute

\section{Source}

National Cancer Institute. Urethral Sphincter. NCI Thesaurus. Code C128573.

One or both of the muscles that surround the urethra and contract to control the flow of urine, either involuntarily (the internal sphincter) or voluntarily (the external sphincter). 